\title{
Somatic cell mutations in cerebral tissue of cattle affected by bovine spongiform encephalopathy
}

\section{Matteo Busconi, Corrado Fogher ${ }^{*}$}

Istituto di Agronomia, Genetica e Coltivazioni erbacee, Sezione di Botanica e Genetica vegetale, Università Cattolica S. Cuore, Piacenza, Italy; *Corresponding Author: corrado.fogher@unicatt.it

Received 16 April 2010; revised 28 April 2010; accepted 6 May 2010.

\begin{abstract}
In animals the prion disease includes sheep and goat scrapie and the bovine spongiform encephalopathy (BSE). While several polymorphisms of the prion (PRNP) gene have been identified in sheep and some of them have been associated with susceptibility to scrapie, few mutations are reported in cattle and no correlation with BSE have been demonstrated. Genetic screening for mutants in the PRNP gene of 21 BSE positive animals by direct sequencing of the amplified gene, using DNA extracted from brain as template, confirmed that only few polymorphisms are present. However DNA molecules cloned and sequenced from the population of fragments considering a total of 90 clones from 9 BSE positive and 70 clones from 7 BSE negative animals, gave a highly significant differences in the frequency of mutations $(p=0.01)$. The high frequency and type of variants found cannot be explained only with misincorporation error of the Taq polymerase. Interestingly one of the mutations found in the BSE positive animals (F209S) corresponds to a mutant that causes a familiar form of prion disease in humans (F198S). These data can be explained with the presence of somatic mutations modifying the PRNP gene in single brain cells.
\end{abstract}

Keywords: BSE; Prion; Somatic Mutations

\section{INTRODUCTION}

The transmissible spongiform encephalopathies (TSE) in humans and animals are caused by anomalous aggregation of a cell-surface protein known as prion protein (PrP). This aggregation is a consequence of a template-induced conformational change of the normally expressed protein $\left(\operatorname{PrP}^{\mathrm{C}}\right)$ into the pathogenic missfolded form $\left(\mathrm{PrP}^{\mathrm{Sc}}\right)$ [1]. In humans the TSE known as Creutzfeldt-
Jakob disease (CJD) has been categorised into three main forms: 1) sporadic cases with no known environmental cause $(85 \%)$ [2]; 2) familial cases with a dominant inherited mutation of the PRNP gene (10-15\%) [3]; 3 ) cases transmitted from a known or presumed environmental source (e.s. iatrogenic, rare) [4]. In animals the prion disease includes sheep and goat scrapie and the bovine spongiform encephalopathy (BSE). While several polymorphisms of the PRNP gene have been identified in sheep and some of them have been associated with susceptibility to scrapie [5], few mutations have been found in cattle and no correlations with BSE have been postulates [6].

Molecular genetic studies of the inherited form of CJD indicate that this disease is caused by mutations in the prion protein gene $(P R N P)$ and the most frequent mutations described are P102L, D178N, F198S, E200K, and V210I [7]. No mutations genetically linked to the disease have been found in animals, but amino acid changes at codons 136, 154 and 171 have been shown to be associated with susceptibility to scrapie in sheep [8]. In contrast to the many PrP polymorphisms found in sheep, only few PrP polymorphisms have been found in cattle regarding the number of octapeptide repeat units (five-seven), present in the first half of the gene [9], or changes in the amino acids S46I and S146N found in healthy animals $[6,10]$. Genetic studies have not shown an association between numbers of repeats and BSE susceptibility $[9,11]$.

A new variant of CJD (nvCJD) has been demonstrated to be caused by the same prion strain that causes BSE rising concern for a possible human epidemic following meat from affected animals entering the human food chain, in late 1980s and early 1990s [12]. In terms of control of BSE it is important to know whether this disease, apart from the origin from infected meat and bone meals, is conditioned by genetic factors. The aim of this work is to show that the brain tissue of BSE affected cattle contains somatic mutations, one of which is homologous to a PRNP mutation responsible for a familial form of prion disease in humans. 


\section{MATERIALS AND METHODS}

\subsection{DNA Extraction}

Twenty-one BSE positive samples diagnosed with rapid methods and confirmed with histopathology, immunohistochemistry and Western blot as described by Casalone et al. [13] and seven BSE negative samples, were used for PCR amplification of the entire PRNP gene (Acc. n. X55882). DNA extraction from obex region of the medulla oblongata in the brain stem has been done with manual Qiagen kits.

\subsection{PCR Amplification}

All the PCR amplifications were performed with a GeneAmp PCR system 9700 thermal cycler (Applied Biosystems). PCR reactions were carried out in a final volume of $20 \mu \mathrm{l}\left(1 \mathrm{X}\right.$ PCR buffer; $2 \mathrm{mM} \mathrm{Mg}{ }^{++}, 150 \mu \mathrm{M}$ dNTPs, 5 pmol of each primer (Forward IGP553 GCTAGCATGGTGAAAAGCCACATAGGCAG, and Reverse IGP554 GTCGACCTATCCTACTATGAGAAAAATGAGG), $1.5 \mathrm{U}$ AmpliTaq Gold (Applied Biosystems) and $5 \mathrm{ng}$ of genomic DNA). The following cycle was applied: $10 \mathrm{~min}$ at $95^{\circ} \mathrm{C}, 35$ cycles of $30 \mathrm{~s}$ denaturation at $95^{\circ} \mathrm{C}, 1 \mathrm{~min}$ at $56^{\circ} \mathrm{C}, 1.5 \mathrm{~min}$ extension at $72^{\circ} \mathrm{C}$. The amplified products were resolved by electrophoresis on agarose gel and visualised by ethidium bromide staining. The expected size of PCR products was $807 \mathrm{bp}$ (795 bp from PRNP gene and $12 \mathrm{bp}$ more from primers). Fragments were recovered from the gel and directly sequenced or ligated in a T-vector (pGEM-T easy, Promega), then transformed by electroporation into $E$. coli strain DH5 $\alpha$. Ten isolated clones were sequenced for each PCR sample reactions of 9 positive and 7 negative animals after plasmid purification. Cycle-sequencing was performed in a final volume of $20 \mu \mathrm{l}$ using the big dye v3 chemistry (Applied Biosystems) and, after purifications, the sequences were loaded and ran on the ABI Prism3100 Genetic Analyzer (Applied Biosystems) following the manufacturer's protocols.

\section{INTERNAL PRIMER DESIGN AND MUTATION SCREENING}

Using the sequence data of the clone with the mutation F209S, presenting a change from $\mathrm{T}$ to $\mathrm{C}$ in position 626 , a reverse internal primer (IGP717 5'-CATCTTGATGTCAGTTTCGGTGG-3') was designed in order to perform a mutation screening.

All the original twenty one positive BSE samples, plus three BSE negative samples, were screened for the presence of the mutation F209S. Reactions were carried out in a final volume of $20 \mu \mathrm{l}$ (1X PCR buffer; $2 \mathrm{mM}$ $\mathrm{Mg}^{++}, 150 \mu \mathrm{M}$ dNTPs, $5 \mathrm{pmol}$ of each primer (IGP553 and IGP717), $1.5 \mathrm{U}$ AmpliTaq Gold. The product of the first reaction (IGP553/554) from different independent amplifications at different dilutions (ranging from $10^{-3}$ to $\left.10^{-9}\right)$ was used as template for PCR. The following PCR touch down program was applied: $10 \mathrm{~min}$ at $95^{\circ} \mathrm{C}, 12$ cycles of $30 \mathrm{~s}$ denaturation at $95^{\circ} \mathrm{C}, 30 \mathrm{~s}$ at $62^{\circ} \mathrm{C}\left(-0.5^{\circ} \mathrm{C}\right.$ for each cycle), $1 \mathrm{~min} 30 \mathrm{~s}$ extension at $72^{\circ} \mathrm{C}$, followed by 35 cycles of $30 \mathrm{~s}$ denaturation at $95^{\circ} \mathrm{C}, 30 \mathrm{~s}$ at $56^{\circ} \mathrm{C}$, $1 \mathrm{~min} 30 \mathrm{~s}$ extension at $72^{\circ} \mathrm{C}$. Amplified products were resolved by electrophoresis on agarose gel.

\section{RESULTS}

Genetic screening for mutants in the PRNP gene of 21 positive BSE animals diagnosed in Italy in the past years, by direct sequencing of the amplified gene fragment using DNA extracted from brain as template, confirmed the previous knowledge that only few polymorphisms are present in cattle. However, some amplified PCR products ( 9 out of 21 ) were not directly sequenced since the signal was not clear due to the heterozygosity of the number of octapeptide repeats. Therefore we decided to clone the PCR product of those 9 samples and to consider single clones for sequencing. The amplified fragments obtained using the DNA recovered from the brain tissue of 7 negative BSE animals of the same age as the positive ones were cloned too and used as control. It is noteworthy to stress that all the amplifications for both positive and negative samples were carried out in the same conditions: using the same reagents, the same amplification cycle and thermal cycler.

By sequencing a total of 90 clones of BSE positive animals and 70 clones of BSE negative animals, we found a highly significant difference in the frequency of mutations ( $p=0.001$, Table 1). 26 out of 90 clones analysed from the BSE positive samples showed nucleotide changes while only 4 out of 70 clones analysed from the BSE negative samples were characterised by sequence variations. Moreover all the mutations from the positive BSE animals, with no amino acid changes, were randomly distributed all over the full sequence, while the mutations with amino acid changes were concentrated mainly in the carboxy-terminal domain of the protein (Figure 1).

So we found that DNA molecules cloned and sequenced from the population of the fragments amplified from a tissue sample of $25 \mathrm{mg}$ (corresponding to about 4 $\times 10^{6}$ cells if we consider the size of the bovine brain cells similar to the human brain cells [14]) from the positive BSE animals contain several single nucleotide polymorphisms (SNP) and interestingly one of these mutations (F209S) corresponds to a mutant which causes a familiar form of prion disease in humans (F198S, Figure 1).

The high frequency and type of variants cannot be due only to misincorporation and frame shift errors of the Taq polymerase since 1) for the BSE negative samples we reported a significantly lower variation rate $\left(\chi^{2}=\right.$ $17.92, p=0.001) ; 2$ ) the distribution of the mutations 


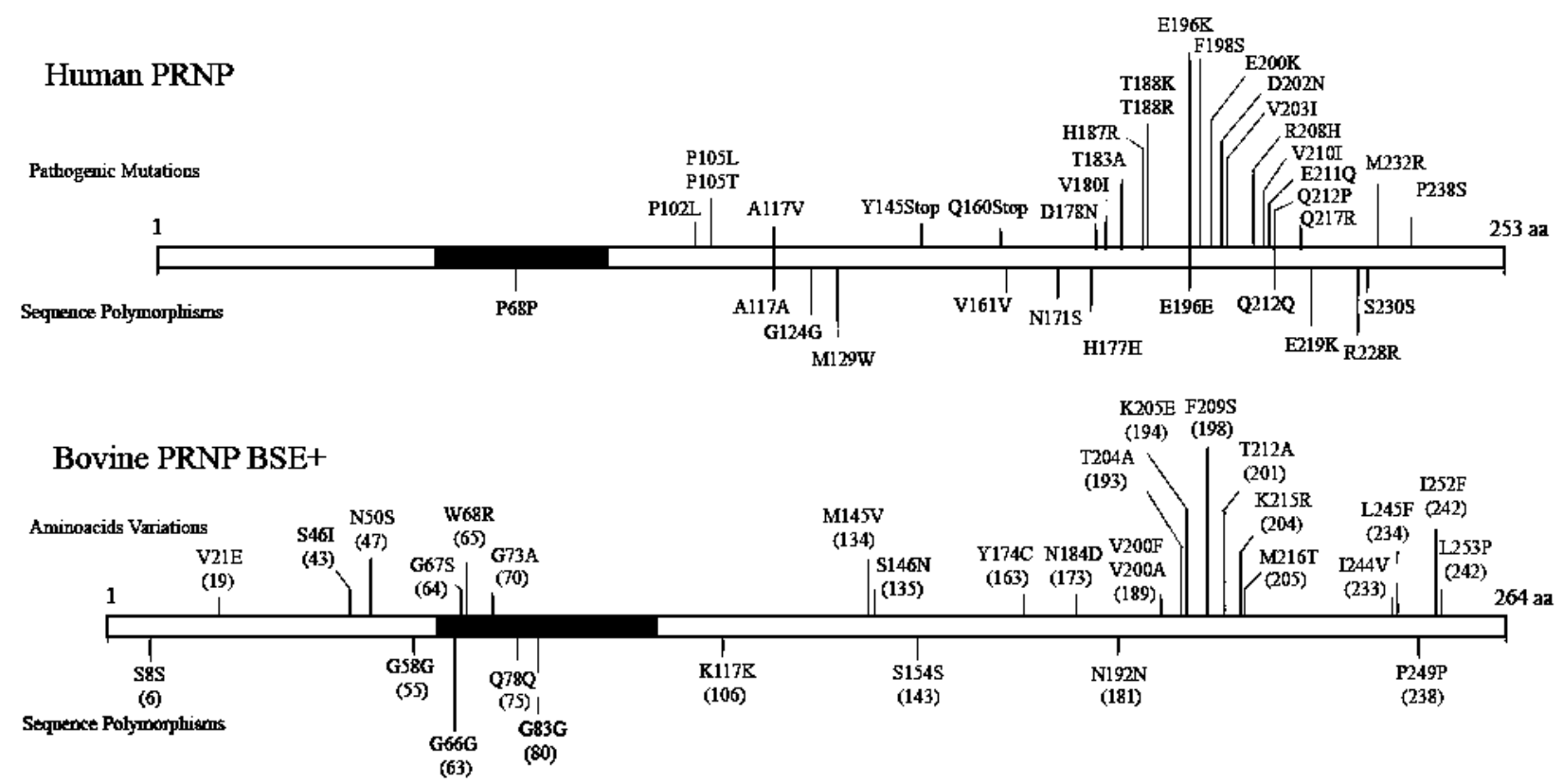

\section{Bovine PRNP BSE-}

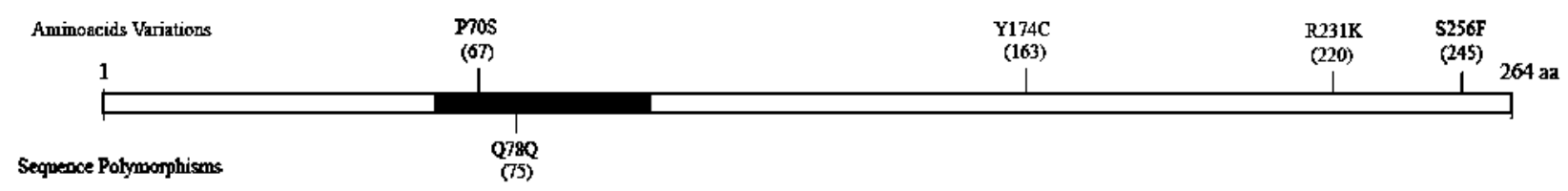

Figure 1. Variations and mutations of the prion protein gene in humans (CJD) and variations and polymorphisms found in cattle positive and negative to BSE. The mutations causing prion disease are above the line of the human sequence. Below the lines are the polymorphisms, some but not all of which are known to influence the phenotype of disease (adapted from 17). For the bovine sequence, the variations determining amino acids changes are above the line and the polymorphisms are below the line. Those found in BSE positive animals by direct sequencing are in green. All the bovine variations and polymorphisms, with the exception of those in position 46 and 146, are from this work. Parentheses in the bovine sequences indicate corresponding human codons.

Table 1. Frequency of mutations and polymorphisms found in amplified and cloned sequences of the $P R N P$ gene from cerebral tissue of positive and negative BSE cattle.

\begin{tabular}{cccc}
\hline Samples & $\mathrm{N}^{\circ}$ of clones sequenced & $\begin{array}{c}\mathrm{N}^{\circ} \text { of variants } \\
\text { found }\end{array}$ & Percentage of variation \\
\hline 9 BSE positive & 90 & 26 & 28.9 \\
7 BSE negative & 70 & 4 & 5.71 \\
\hline
\end{tabular}

with amino acid changes shows hotspot areas, the major of which corresponding to the human gene hotspot mutation area (codon 174 to 264, Figure 1); 3) all the observed variants are base substitutions, with no frameshift errors [15]; 4) if misincorporation was the only mutants cause, there would be an even distribution of changes in the three codon positions $(1: 1: 1)$ instead of the 1.6:1.2:0.2 found in the hotspot area with a $\chi^{2}$ of $5.2(\mathrm{p}=$ $0.1)$; 5) the $K_{A} / K_{S}$ ratio [16], where $K_{A}$ is the number of non-synonymous substitutions per non-synonymous site $(20 / 508.5=0.0393)$ and $K_{S}$ is the number of synonymous substitutions per synonymous site $(6 / 283.5=$
$0.0211)$, is greater than $1.0(1.86)$.

Furthermore based on the sequence of the mutant F209S, we designed a reverse primer and we used it in a mutation screening on all the $21 \mathrm{BSE}$ positive plus 3 negative samples. Using the genomic DNA as template for the reaction, we replicated the PCR three times independently and obtained always the amplification of the expected $627 \mathrm{bp}$ fragment only for the sample in which the mutation was originally found (animal n. 7) and never on the other positives and negatives (Figure 2). The mutation screening was performed also using the product of the first reaction (IGP553/554) at different 


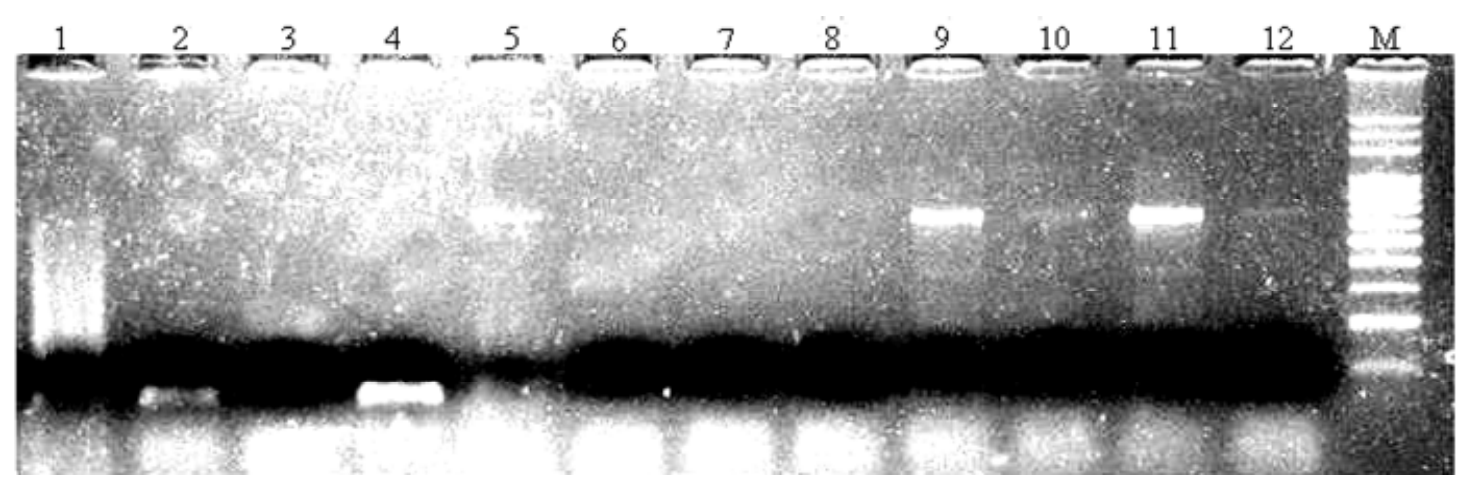

Figure 2. Results of the PCR mutation screening for the variant F209S using the primer IGP553-IGP717. Lines 1-4: negative control with the PCR product of a BSE negative animal at serial dilutions $\left(1: 10^{-6} ; 2: 10^{-7} ; 3: 10^{-8} ; 4\right.$ : $\left.10^{-9}\right)$. Lines 5-8: BSE positive animal n. 15 at serial dilutions $\left(5: 10^{-6} ; 6: 10^{-7} ; 7: 10^{-8} ; 8: 10^{-9}\right)$. Lines 9-12: BSE positive animal n. 7 at serial dilutions $\left(9: 10^{-6} ; 10: 10^{-7} ; 11: 10^{-8} ; 12: 10^{-9}\right)$. Line M: 100 bp ladder.

dilutions (ranging from $10^{-3}$ to $10^{-9}$ ) as template for PCR, again we obtained the amplification only for the expected sample and never in the remaining with the exception of positive n. 15 were at some sample dilutions the band appears (Figure 2).

Considering that different amino acid variations could alter more or less heavily both the structure and the functionality of the protein, we analysed the mutated sequences with the software CODDLE (Codon Optimized to Discover Deleterious Lesions, www.proweb. org/coddle) in order to have some information about the most putative dangerous mutations. Analysing the sequence of the bovine prion gene against the prion block (IPB000817, from BLOCKS Database Version 14.3) the software identifies the presence of five highly conserved amino acid blocks and shows all the possible deleterious changes according to the mutation method selected. The analysis was repeated considering several mutation methods and, finally, 9 out of 20 amino acid changes we have found were considered important for the function of the protein: N50S, M145V, Y174C, V200A, F209S, T212A, M216T, I252F, L253P.

\section{DISCUSSION}

A possible explanation of the sequence variations found in the analysed clones could be a polymerase error during amplification or the presence of somatic cell mutations in the cerebral tissue.

The first hypothesis do not explains 1) the great difference in the variation rate between positive and negative samples amplified in the same conditions and considering a similar number of clones analysed, 2) the distribution of the putative amino acid variation is very correspondent to the distribution of human pathogenic mutations (Figure 1) defining a main hotspot area in the carboxy-terminal region of the protein, and 3 ) the use of a selective primer designed on a mutation which correspond to a pathogenic human mutation gives amplification always in the expected sample and never in the oth-

\section{ers (Figure 2).}

Furthermore 8 out of 9 of the most dangerous putative mutations predicted by using the software CODDLE were grouped in the second part of the gene and this agree with the situation found in human prion gene where all the pathogenic mutations up to now are in the second part of the gene (Figure 1).

To our opinion the reported data on sequence variants can be explained with the presence of somatic mutations modifying the PRNP gene in single cells. These somatic mutations will usually be unnoticed because they are surrounded by millions of normal cells, producing the $\mathrm{PrP}^{\mathrm{Sc}}$ isoform that causes disease by amplification of the somatic genetic effect with seeding of the $\operatorname{PrP}^{\mathrm{C}}$ protein in the surrounding cells. Somatic mutations have been assumed also due to the origin of CJD [17]. Somatically generated variations, determining a seeding point from which the pathological form of the protein spreads around, can produce enough protease-resistant $\mathrm{PrP}^{\mathrm{Sc}}$ to allow diagnosis of the pathology with hysto- and immuno-techniques. In order to investigate the role of these somatic mutations, a higher number of animals, including BSE negative animals both exposed and unexposed to the risk factor will be analysed. Depending on being an early or late event in the cerebral development, the somatic area of the mutated cells can be limited or expanse. This will be further studied coupling sequencing and Western analysis of fine topographical sections of BSE positive brains.

\section{ACKNOWLEDGEMENTS}

We wish to thank P.L. Acutis and M. Caramelli of CEA, Centro di Referenza Encefalopatie Animali, for providing the positive samples. This work was supported by a MIUR grant to Chelab Srl.

\section{REFERENCES}

[1] Prusiner, S.B. (1982) Novel proteinaceous infectious 
particles cause scrapie. Science, 216(4542), 136-144.

[2] Will, R.G. (1998) Oral infection by the bovine spongiform encephalopathy prion. In: Brown, F., Griffiths, E., Horaud, F. and Petricciani, J.C., Ed., Safety of Biological Products Prepared from Mammalian Cell Culture, Karger Publishers, Basel, 79-84.

[3] Will, R.G., Alperovitch, A., Poser, S., Pocchiari, M., Hofman, A., Mitrova, E., de Silva, R., D’Alessandro, M., Delasnerie-Laupretre, N., Zerr, I. and van Duijn, C. (1998) Descriptive epidemiology of Creutzfeldt-Jakob disease in six European countries, 1993-1995. Annals of Neurology, 43(6), 763-767.

[4] Brown, P., Preece, M.A. and Will, R.G. (1992) "Friendly fire" in medicine: Hormones, homografts, and CreutzfeldtJakob disease. Lancet, 340(8810), 24-27.

[5] Hunter, N. (1997) PrP genetics in sheep and the implications for scrapie and BSE. Trends in Microbiology, 5(8), 331-334.

[6] Heaton, M.P., Leymaster, K.A., Freking, B.A., Hawk, D.A., Smith, T.P.L., Keele, J.W., Snelling, W.M., Fox, J.M., Chitko-McKown, C.G. and Laegreid, W.W. (2003) Prion gene sequence variation within diverse groups of US sheep, beef cattle, and deer. Mammalian Genome, 14(11), 765-777.

[7] Mastrangelo, P. and Westaway, D. (2001) The prion gene complex encoding $\operatorname{PrP}(\mathrm{C})$ and Doppel: Insights from mutational analysis. Gene, 275(1), 1-18.

[8] Belt, P.B., Muileman, I.H., Schreuder, B.E., Bos-de Ruijter, J., Gielkens, A.L. and Smits, M.A. (1995) Identification of five allelic variants of the sheep PrP gene and their association with natural scrapie. Journal of General Virology, 76, 509-517.

[9] Neibergs, H.L., Ryan, A.M., Womack, J.E., Spooner, R.L. and Williams, J.L. (1994) Polymorphism analysis of the prion gene in BSE-affected and unaffected cattle. Animal Genetics, 25(5), 313-317.

[10] Hills, D., Schlaepfer, J., Comincini, S., MacLean, I., Dolf, G., Ferretti, L., Olsaker, I. and Williams, J.L. (2003) Sequence variation in the bovine and ovine PRNP genes. Animal Genetics, 34(3), 183-190.

[11] Hunter, N., Goldmann, W., Smith, G. and Hope, J. (1994) Frequencies of PrP gene variants in healthy cattle and cattle affected by BSE in Scotland. The Veterinary Record, 135, 400-403.

[12] Collinge, J., Sidle, K.C.L., Meads, J., Ironside, J. and Hill, A. F. (1996) Molecular analysis of prion strain variation and the aetiology of "new variant" CJD. Nature, 383(6602), 685-690.

[13] Casalone, C., Zanusso, G., Acutis, P.L., Ferrari, S., Capucci, L., Tagliavini, F., Monaco, S. and Caramelli, M. (2004) Identification of a second bovine amyloidotic spongiform encephalopathy: Molecular similarities with sporadic Creutzfeldt-Jakob disease. Proceedings of the National Academy of Sciences of the United States of America, 101(9), 3065-3070.

[14] Kalumuck, K.E., Fallon, L.F., Jr., Piotrowski, N.A., Rizzo, C.M.D., Carson, C.C. and Irons-Georges, T. (1998) Magill's medical guide. Revised Edition, Salem Press, Hackensack, 221 .

[15] Tindall, K.R. and Kunkel, T.A. (1988) Fidelity of DNA synthesis by the Thermus aquaticus DNA polymerase. Biochemistry, 27, 6008-6013.

[16] Messier, W. and Stewart, C.-B. (1997) Episodic adaptive evolution of primate lysozymes. Nature, 385(6612), 151154.

[17] Prusiner, S.B. (1997) Prion diseases and the BSE crisis. Science, 278(5336), 245-251. 